\title{
Practical steps and collegiality in the building of podiatry curricula to meet accreditation and health sector employability demands.
}

\author{
Anita Raspovic ${ }^{1}$, Linda Pannan ${ }^{1}$ \\ a.raspovic@latrobe.edu.au; l.pannan@latrobe.edu.au \\ ${ }^{1}$ La Trobe University
}

\begin{abstract}
Historically, mixed arrangements have been in place between educational institutions and podiatrist registration bodies to evaluate the capacity of courses to adequately prepare new graduates for clinical practice. The national scheme for the registration of health practitioners introduced in 2010, followed by a national system for accreditation of respective courses, has however seen significant legislative and policy change to requirements for evidencing effectiveness of podiatry courses. In addition, there has been a local and international change in emphasis by stakeholders in higher education, government, professional regulation, quality assurance and employment, towards measureable, explicit student learning outcomes. Curricula initiatives at La Trobe University, including large scale systematic review and redesign of all courses commencing in 2005 within the Faculty of Health Sciences, and a subsequent university wide 'Design for Learning' project (La Trobe University, 2009), provided a timely platform for podiatry staff to respond to critical emerging imperatives for increased program transparency and accountability.
\end{abstract}

The case study presented in this paper provides a practical, in-context explanation of an approach adopted to develop and embed Podiatry Course Learning Outcomes (CLOs). It draws on the podiatry profession's competency standards and produces aligned curricula where fine grain subject Intended Learning Outcomes (ILOs), underpinned by related learning and assessment activities, cumulatively address student development of the CLOs. Systematic and comprehensive documented evidence demonstrates when and how key podiatry competencies are developed, attained and assessed in these podiatry curricula.

Key words: Embedding course learning outcomes, graduate outcomes, curriculum design, curriculum mapping, podiatry competency standards, professional accreditation

\section{Introduction}

The impetus for change was growing, when in the mid to late 2000's the Podiatry Department at La Trobe University was considering how to best approach; curriculum redesign and renewal initiatives from within its faculty and university, important legislative changes to professional regulation and program accreditation, rapidly evolving needs of health care practitioner education, and fundamental shifts in higher education from input to outcome based education. A comprehensive approach incorporating transparency and accountability was needed at a number of levels, to evidence that their courses had the capacity to achieve the stated outcomes. Specifically, they needed to be able to show that by the time of graduation, students of the podiatry courses could demonstrate the attainment

Raspovic, A. \& Pannan, L. (2013). Practical steps and collegiality in the building of podiatry curricula to meet accreditation and health sector employability demands 
of the full range of discipline specific professional competencies, generic skills and attributes required of an effective contemporary health care practitioner. Moreover, this approach needed to bring strong educational value to the design and development of the newly developed curricula, thereby enhancing validity and credibility of the new courses.

This paper aims to offer a practical case study in response to the question: What are the significant curriculum design, development and implementation processes which can facilitate identifying, embedding and evidencing CLOs throughout two vocationally oriented health science courses? As a result of reflection during and after the process, the paper also offers insights into anticipated and unexpected outcomes. The discussion below begins by providing introductory information on the profession of podiatry, although principles in this paper transcend discipline boundaries. The sections that follow offer contextual background that was important in shaping the approach used. Detail is given of the method adopted to create the Podiatry Course Learning Outcomes (CLOs), how the systematic process that ensures the learning required to achieve them is embedded and assessed throughout the courses, and how this collectively meets external demands for increased program accountability and transparency.

\section{The podiatry context}

A podiatrist is a health professional who deals with the prevention, diagnosis, treatment and rehabilitation of medical and surgical conditions of the feet and lower limbs (Australian Podiatry Association, 2012). While podiatry originated from the very old practice of chiropody, significant changes to the breadth, depth and complexity of practice has seen the emergence of a relatively new professional field of health. In Australia, podiatry has been in existence for around 35 years, since changing its name from chiropody and has rapidly developed its scope of practice over that time (Schnock, 1989). Today, podiatrists are primary care practitioners who work in various clinical settings, dealing with a range of people, clinical conditions and types of management modalities. This includes care of people of all ages from children to adults and the elderly. Podiatrists assist in the management of a range of complaints including; sports injuries, complications from chronic conditions such as diabetes and arthritis, musculoskeletal pain, and skin and nail concerns. Anyone who has a foot problem or is seeking to maintain foot wellness might consult with a podiatrist.

With the evolution of the profession over time, podiatrists have also become more involved in aspects of patient care that carry increased levels of risk. Many podiatrists work with medically compromised patients, at significantly elevated risk of complications such as serious infection, non-healing wounds and amputation. Podiatrists are trained to work with sharp instruments and use invasive techniques, such as the injection of local anesthetic and the conduct of minor surgical procedures. Stringent infection control protocols exist around dealing with blood and bodily fluids. Entry-level training now contains preparatory education for podiatrists who may, with further post-qualification study and experience, prescribe a selection of Schedule 4 (S4) medications such as antibiotics. Ongoing medical and technical developments have seen an array of sophisticated diagnostic and management strategies develop for a myriad of applications. The complexity of podiatric practice has grown quickly over a relatively short period of time, placing ongoing demands on podiatry courses to prepare students for contemporary practice. The very high expectations of quality podiatric education are indicative of its significance for public health and safety.

\section{The context of change}

\section{A changing regulatory landscape in health}

Traditionally the training and education of podiatrists in Australia occurred within a range of institution types, including the former TAFE sector or at external schools such as the former Lincoln School of Health Sciences in Melbourne. As a consequence of gaining status as a

Raspovic, A. \& Pannan, L. (2013). Practical steps and collegiality in the building of podiatry curricula to meet accreditation and health sector employability demands

Journal of Teaching and Learning for Graduate Employability, 4(1), 58-72. 
registered health profession in 1977 in Victoria, the educational requirements for podiatry students increased from Diploma to Bachelor level in Melbourne in the 1980s, shortly before the program moved into the higher education sector and was established in the Faculty of Health Sciences at La Trobe University. Professional registration throughout Australia operated with the primary function of protecting the public and creating a regulatory watchdog for the profession, setting legislative requirements for the attainment of appropriate levels of education and formalising expectations around standards of practice.

The number of podiatry courses in Australia was relatively stable at around six until more recent emergence of new courses offering a greater range of course structures and qualification levels in the education of entry-level podiatry practitioners. In 1994 the peak professional body representing podiatrists in Australia and New Zealand, the Australasian Podiatry Council (APodC), released the first set of Australian competency standards, entitled 'Competency Standards and Related Assessment Methods for the Australian Podiatry Profession'. These articulated minimum expected capabilities of entry-level practitioners nationally, and prompted the launch of a voluntary accreditation program for podiatry courses in the early 2000 s.

In 2008, national laws created in response to the outcomes from the Council of Australian Governments (COAG) Productivity Commission review of the Australian Health Workforce, resulted in a new national registration and accreditation scheme for health practitioners. This scheme is concerned with the ongoing development of a sustainable, flexible and responsive health workforce, the facilitation of high quality education and the provision that only practitioners who are suitably trained to undertake competent and ethical practice are registered (Forrester \& Griffiths, 2011). It affords greater mobility to podiatrists who can register nationally and practice throughout Australia. Accreditation of podiatry courses in Australia became compulsory from July 12010 and once fully rolled out, Australian courses must hold current accreditation status with the Australian and New Zealand Podiatry Accreditation Council (ANZPAC) and the Podiatry Board of Australia, for its graduates to be eligible for podiatrist registration, a legal requirement to practice as a podiatrist.

ANZPAC has two primary standards documents of relevance to entry-level course accreditation; the 'ANZPAC Podiatry Competency Standards for Australia and New Zealand' (ANZPAC 2009a - updated 2012) and the 'ANZPAC Accreditation Standards and Procedures for Podiatry Programs for Australia and New Zealand' (ANZPAC 2009b). The accreditation standards cover five broad domains, addressing a comprehensive suite of issues around the provision of podiatry courses and requiring evidence of links between the ANZPAC competency standards and curricula framework including; contemporary content, learning and teaching approaches, sequencing, clinical education and approaches to assessment. The ANZPAC accreditation standards state the requirement that the Total curriculum provides sufficient learning opportunities for students to meet minimum competency standards (in sub-standard C.1. ANZPAC, 2009b).

The challenge therefore was to mount a case, supported by what would be deemed an acceptable level of evidence, that the profession's competency standards are appropriately addressed through the new podiatry courses.

\section{Changing contemporary health care practice, and future needs}

Constant developments in the health sector, such as the evolving field of podiatry and the expansion and diversity of interdisciplinary health care teams, add complexity to the work of a podiatrist which is more complex now than it has ever been, and will continue to be so (Brooks, 2011). It is particularly necessary for vocational courses such as podiatry to stay connected with industry, where there is great emphasis on education facilitating preparedness for employment in health practitioner roles. Contemporary practice must be identified and articulated before competency standards can be interpreted in its context.

Raspovic, A. \& Pannan, L. (2013). Practical steps and collegiality in the building of podiatry curricula to meet accreditation and health sector employability demands

Journal of Teaching and Learning for Graduate Employability, 4(1), 58-72. 
Significantly, a large portion of practical education in the courses is provided through fully operating clinics, and the curriculum must adequately prepare students early to function adequately and safely in contemporary health environments.

Contemporary health practice requires podiatrists to be able to work in teams to effectively solve complex problems and generate new solutions. Good communication, professionally appropriate conduct and strong interpersonal skills are expected in what are often new and unfamiliar environments. Navigating the 'in between the lines' unwritten operational rules in places of work, and understanding hierarchy, power and ways to influence change are highly sophisticated elements that are pervasive to most work environments. Information literacy, evidence-based practice, enquiry skills, critical analysis and understanding research are key elements to well-rounded practitioners. The demand for these attributes from stakeholders, including employers, government health agencies and funding bodies, is clear and will continue to increase as podiatrists are required to be more flexible and adaptable within the health workforce. Although implicit integration of these work related elements was likely to have previously occurred in traditional courses, it was clear that strategies to demonstrate that the new curricula would deliver the needs of a contemporary health care workforce were required. Hence, discussions around what an effective podiatry course should be able to do now and in the future also considered how to provide convincing evidence that the courses would deliver on these promises.

\section{A fundamental shift in higher education from input to outcome}

Simultaneously, curricula design was evolving (Biggs \& Tang, 2007; Hubball \& Burt, 2004; Jones et al., 2007). The notable shift in higher education towards outcomes-based education strongly influenced this podiatry curriculum development effort. The Australian based 'Assessing and Assuring Graduate Learning Outcomes' project states this shift of emphasis from teaching inputs to learning outcomes has been a characteristic of considerable international activity aimed at articulating discipline specific statements of the learning outcomes university students should demonstrate by the time of graduation (AAGLO project, 2011). Recent works conducted through the Australian Learning and Teaching Council (ALTC) supported projects, 'Assuring Graduate Attributes' (Oliver, 2011) and 'Learning and Teaching Academic Standards' (ALTC, 2011), have articulated generic graduate outcomes and threshold learning outcomes for a selection of disciplines respectively. Critical shifts in regulation, policy and quality assurance in higher education confirms this view with the expected use of explicit learning outcomes, specifically by the new Tertiary Education Quality and Standards Agency (TEQSA, 2011).

While quality teaching inputs and a range of other key elements are essential drivers of quality student learning, defining and measuring the end product in the form of student learning outcomes has strong merit. But if this latter approach is adopted, can it provide the accountability and transparency measures useful for program approval, curriculum development processes, and professional accreditation? And, can these tools help to communicate to students, clinical supervisors, the profession and patients, in tangible terms, what the courses achieve?

\section{Opportunities to strengthen curriculum aligns with institutional curriculum renewal}

Podiatry at La Trobe University was well placed to respond to the above issues as a review of all courses offered by the Faculty of Health Sciences resulted in major curriculum change, with implementation to start in 2009. Podiatry was to be offered as a combined Bachelor/ Master qualification with a graduate entry pathway into the Masters course, a new course structure for the discipline at the time. Along with a shift to an enquiry-based delivery model, the program was offered across geographically dispersed campuses, making use of block and sandwich teaching modes. There was also greater reliance on disseminated learning and teaching strategies, with the students located externally at clinical placements for longer,

Raspovic, A. \& Pannan, L. (2013). Practical steps and collegiality in the building of podiatry curricula to meet accreditation and health sector employability demands

Journal of Teaching and Learning for Graduate Employability, 4(1), 58-72. 
and planning for learning and instruction also focused on the higher levels on the AQF framework. In addition, there was a high level of commitment to embedding graduate attributes and generic capabilities to address the evolving common needs of health care practitioners. There was strong support within the faculty to shift to an outcomes-based approach. Curriculum mapping and re-design that involved making CLOs explicit, aligning learning activities with assessment tasks, and addressing overlaps and gaps in content and skills, were expected.

\section{The curriculum design process}

Backwards curriculum design principles were adopted (Kelley et al., 2008a) in the development of custom designed curricula that would meet the requirements, as outlined above, drivers and circumstances, and achieve the clearly specified outcomes.

\section{Stage one: Developing the Podiatry Course Learning Outcomes (CLOs)}

As a first step, the La Trobe University Podiatry CLOs were strategically created. These CLOs captured, by design, (i) the podiatry profession's competency standards (ANZPAC 2009 a,b), (ii) key generic attributes of a contemporary health care practitioner (Faculty of Health Sciences 2009), and (iii) capabilities of a university graduate (La Trobe University, 2009, 2012).

\section{Characteristics and presentation of the Podiatry Course Learning Outcomes (CLOs)}

Research reports that agreement on the nature of graduate learning outcomes is far from universal with academics' conceptualisations ranging from basic communication skills to the transformational outcomes that shape personal and professional identity (AAGLO project 2009).

The first challenges when developing the Podiatry CLOs were to identify and articulate what podiatry students would be expected to know and be able to do, including attributes and qualities, by the end of their podiatry course, and to also consider the structural parameters and characteristics of the Podiatry CLOs. That is with no single accepted format for the learning outcomes there was good scope to customise them. Of primary importance were fit to purpose and practical utility. Physical size of the document, the number of CLOs, the level of detail that might be provided and their sequential development throughout the course, were all important considerations.

These CLOs were to be created and presented in a manner that would embody the complex domains of what it means to be an effective, reflective and ethical health care practitioner and learner, understanding that at times they deal with elements that are abstract and tacit in nature. This was not to be a mechanical, reductionist checklist of tasks that students must perform, but rather a range of encompassing related statements, capturing forward-focused contemporary health practice. Juxtaposed with this was the influence of the vocational nature of the courses, the importance of systematic skill and practical capability development, and uppermost, future patient safety and well-being. The document had to make sense to a range of audiences, requiring clear and accessible language and phrased in outcomes-based terms that could be demonstrated and assessed. The final CLO document needed to be granular enough to inform curriculum development at the subject level but required intuitive flexibility for interpretation and contextually suitable application. The aim was to design a resource that would be of maximal use for program approval, and curriculum construction and accreditation. 
Creating the Podiatry CLOs was a somewhat organic process that continued over a month or so. The first stage was of information gathering around how others had approached this issue, possible structure, content focus and presentation. In particular good guidance was received from colleagues within the faculty who were facing similar issues. A review of experiences and processes at other universities provided an appreciation of broader issues, such as ensuring stakeholder ownership and realistic discipline contextualisation (Barrie, 2004). Key resources were gathered including; ANZPAC Competency and Accreditation Standards (ANZPAC 2009 a,b), resources on university and faculty strategic directions and graduate capabilities (La Trobe University, 2009, 2012), the Faculty of Health Sciences Graduate Attributes (Faculty of Health Sciences 2009) and relevant literature (Hubball \& Burt, 2004; AQF Advisory Board 2007). Curriculum documentation for the new podiatry courses was on hand as a practical point of reference. The podiatry course structure is essentially offered over four years, with a combined Bachelor/Master degree clinical stream, a combined Bachelor/Master degree research stream (adding six months) and a graduate entry Masters course (years three and four). The CLOs were to be the same for each podiatry course with regard to the requirements of a forward-focused, contemporary entrylevel practitioner, however, the embedding and mapping process was considered separately for each qualification, as were the entrance requirements for the graduate entry master pathway.

Eliciting concepts for the overarching CLOs involved consulting various documents initially. This was conducted by the authors, the Faculty Education/Curriculum Designer and the Podiatry Course Coordinator. Several iterations evolved with the final version merging the eight ANZPAC Competency Standards with the five Health Sciences Graduate Attributes and the six university Graduate Capabilities. Significant overlap existed and merging the key themes was mostly a matter of reconciling terminology difference. The nine selected overarching learning outcome categories for the Podiatry Courses are:

1. Generic health sciences discipline competencies

2. Communication

3. Professional practice

4. Life-long learning

5. Ethical and social responsibility

6. Patient interview and assessment

7. Interpretation, analysis and diagnosis

8. Management and planning evaluation

9. Safe and effective treatment

Consultation with the Podiatry academic staff and the La Trobe University Podiatry External Course Advisory Committee (PECAC) on the detailed wording of the CLO descriptors provided agreement on a final set of nine Podiatry CLOs of mixed generic and discipline focus, which includes the five adopted La Trobe Health Sciences Graduate Attributes. As discussed earlier, the resource presenting the final set of Podiatry CLOs would be used for multiple purposes and must make sense to a range of audiences. The CLOs could be presented as a simple list. However, as ability would also be addressed for each CLO at four increasingly developed cognitive levels (Bowden et al., 2000) a matrix format covering an A3

Raspovic, A. \& Pannan, L. (2013). Practical steps and collegiality in the building of podiatry curricula to meet accreditation and health sector employability demands 
page was found to be most suitable for presenting the detail resulting in the Podiatry Course Learning Outcomes Matrix. Each CLO appears as the header of a column in the $9 \times 4$ cell matrix and the four cells below it identify the abilities achieved at increasing cognitive levels, scoping, enabling, integrating, and relating (see Figure 1). These levels indicate how students may move towards attaining the final CLO. At the most accomplished level the 'relating' ability statements articulate what the students will do to demonstrate they have achieved the relevant CLO. The ability statements at each level are, in essence, fine-grain learning outcomes, incrementally describing the learning path to achieving the CLO. Representing outcome development in this way supports the use of a range of learning experiences in the curriculum leading to the achievement of the final CLOs, and acknowledges that these multi-dimensional outcomes require staged scaffolding throughout an entire course.

Figure 1: A Shell Illustrating the Layout of the Podiatry Course Learning Outcomes Matrix.

\begin{tabular}{|c|c|c|c|c|c|c|c|c|c|}
\hline $\begin{array}{l}\text { QUALITATIVE DESCRIPTION } \\
\text { OF COURSE LEARNING } \\
\text { OUTCOME }\end{array}$ & 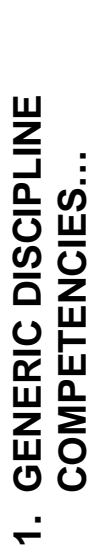 & 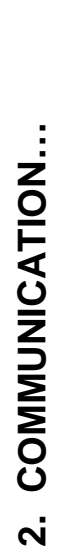 & 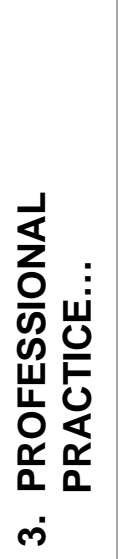 & 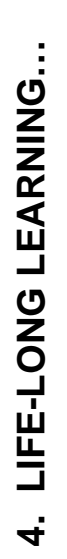 & 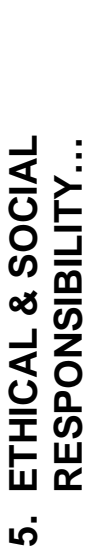 & 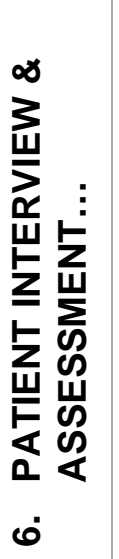 & 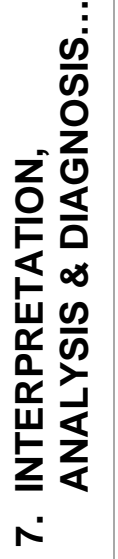 & 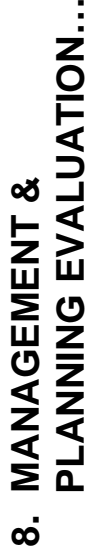 & 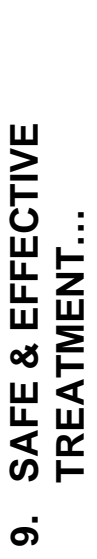 \\
\hline $\begin{array}{l}\text { LEVEL 1: Scoping. } \\
\text { Describe the depth, breadth } \\
\text { and purpose of the CLO, and } \\
\text { the key skills required. }\end{array}$ & & & & & & & & & \\
\hline $\begin{array}{l}\text { LEVEL 2: Enabling. } \\
\text { Perform the requisite skills } \\
\text { by applying them to simple, } \\
\text { directed tasks. }\end{array}$ & & & & & & & & & \\
\hline $\begin{array}{l}\text { LEVEL 3: Integrating. } \\
\text { Apply a combination of skills } \\
\text { in a cohesive manner to } \\
\text { solve problems within own } \\
\text { discipline. }\end{array}$ & & & & & & & & & \\
\hline $\begin{array}{l}\text { LEVEL 4: Relating. } \\
\text { Evaluate new } \\
\text { multidisciplinary situations, } \\
\text { and devise and implement } \\
\text { solutions by applying a } \\
\text { combination of skills, at } \\
\text { beginning practitioner level. }\end{array}$ & & & & & & & & & \\
\hline
\end{tabular}

Raspovic, A. \& Pannan, L. (2013). Practical steps and collegiality in the building of podiatry curricula to meet accreditation and health sector employability demands 
The next stage was to draft the ability statements for each CLO at the four cognitive levels. The last row of the matrix was embarked on first. This row presents the relating level, where expectations of students' capabilities and attributes upon graduation are articulated. Once again several resources were considered in creating the initial statements, with close attention to incorporating elements and performance criteria of each ANZPAC Competency Standard, the Health Sciences Graduate Attributes and emerging University Graduate Capabilities. Informal consultation occurred with Podiatry staff as a gauge of the appropriateness of the directions of the document. Once these graduate level abilities were defined, the Course Coordinator drafted ability statements for the scoping, enabling and integrating levels in consultation with the Faculty Education/Curriculum Designer. A first draft document was created.

The consultations that followed were very important to developing an early version of the Podiatry Course Learning Outcomes Matrix. Several day long meetings were held with Podiatry academic staff to consider debate, alter and qualify the ability statements underpinning CLO 6-9, with those for CLO 1-5 already defined as part of the Health Sciences Graduate Attributes. Several drafts were written, each one refining the wording, scope and intent. Then the views of PECAC were canvassed, including student and broad stakeholder representation. As the document was substantially informed by the profession's competency standards, it was felt that the CLOs and ability statements were, by design, a good reflection of the views of the profession, the podiatry regulatory authority and accreditation agency. The validity of this assumption would be duly tested during the formal podiatry course accreditation process.

This period of consultation and redraft saw the final version of the current Podiatry CLO descriptors and Matrix developed. The matrix document lists nine CLOs, each containing between three and seven ability statements at each of the four cognitive levels. A total of 152 sequenced ability statements eventuated. These were written cognisant that early level abilities should reflect AQF level 5 ability and later ones mostly AQF level 9 . The accuracy of this delineation was cross checked later when the delivery of respective CLOs was mapped to course year level, however no further adjustment of the complexity of outcome ability statements was warranted. Figure 2 gives an example of one of the fully populated CLO columns, revealing its learning path in the form of a sequence of ability statements.

\section{Stage Two: Embedding Podiatry Course Learning Outcomes by curriculum mapping}

Embedding and mapping the podiatry CLOs through each year and subject of the podiatry courses involved a process of assigning each CLO's set of ability statements to relevant sequences of subjects. This occurred alongside an iterative process of developing fine grain learning outcomes for each subject.

A systematic approach that would be sustainable over time was required to ensure outcomes were sequentially delivered, re-enforced, extended and assessed. The literature reports many ways to embed and map curriculum objectives and collectively these were consulted throughout development of the process (Harden, 2001; Sumison \& Goodfellow, 2004; Robley, Whittle \& Murdoch-Eaton, 2005; Kelley et al., 2008b; Spencer, Riddle \& Knewstubb, 2012). The approach adopted followed a step wise focus by year, subject and discrete Subject Intended Learning Outcomes (subject ILOs). At this stage the curriculum was developed to the stage where subjects had been created in each year, with notional ideas about what each subject aimed to achieve. Subject coordinators and staff had gone some way to proposing subject ILOs although this was a work in progress.

Through a series of intensive staff workshops, the first undertaking was to approximate the year level/s with the expected CLO cognitive levels and determine where the learning for

Raspovic, A. \& Pannan, L. (2013). Practical steps and collegiality in the building of podiatry curricula to meet accreditation and health sector employability demands

Journal of Teaching and Learning for Graduate Employability, 4(1), 58-72. 
Figure 2: Learning Path for Podiatry Course Learning Outcome 6, Patient Interview and Assessment.

\begin{tabular}{|c|c|}
\hline $\begin{array}{l}\text { QUALITATIVE } \\
\text { DESCRIPTION } \\
\text { OF COURSE } \\
\text { LEARNING } \\
\text { OUTCOME }\end{array}$ & $\begin{array}{l}\text { 6. PATIENT INTERVIEW \& ASSESSMENT } \\
\text { Podiatry graduates are expected to be able to conduct } \\
\text { contextually sensitive history taking and assessments to evaluate } \\
\text { the patient's podiatric presentation. }\end{array}$ \\
\hline $\begin{array}{l}\text { LEVEL 1: } \\
\text { SCOPING }\end{array}$ & $\begin{array}{l}\text { i. Describe the defined normal range of structure and function of the } \\
\text { foot and lower limb } \\
\text { ii. Describe the purpose of collecting patient history, conducting } \\
\text { assessment, and tailoring of the patient consultation to the } \\
\text { individual's needs, the situation and setting } \\
\text { iii. List the range of questions and assessment techniques that may } \\
\text { apply to podiatric consultation } \\
\text { iv. Describe the features of a clinically useful assessment technique, } \\
\text { such as reliability, validity, sensitivity, specificity, and predictive } \\
\text { capacity. } \\
\text { v. Define characteristics of the patient, situation and / or setting that } \\
\text { may influence the process of interview and assessment }\end{array}$ \\
\hline $\begin{array}{l}\text { LEVEL 2: } \\
\text { ENABLING }\end{array}$ & $\begin{array}{l}\text { i. Formulate a set of interview questions for a given patient } \\
\text { ii. Describe the purpose and features, such as reliability and validity, } \\
\text { of specific assessment techniques } \\
\text { iii. Perform patient interview and document history } \\
\text { iv. Safely perform assessment techniques to provide clinically useful } \\
\text { information } \\
\text { v. List limitations of specific assessment techniques and suggest } \\
\text { alternative options where available }\end{array}$ \\
\hline $\begin{array}{l}\text { LEVEL 3: } \\
\text { INTEGRATING }\end{array}$ & $\begin{array}{l}\text { i. Select and justify the choice of questions used in the patient } \\
\text { interview } \\
\text { ii. Select and justify choice of assessment techniques for a given } \\
\text { patient } \\
\text { iii. Present and explain assessment results } \\
\text { iv. Discuss why the defined normal and abnormal ranges of structure } \\
\text { and function may or may not correlate with a patient's presenting } \\
\text { complaint } \\
\text { v. Relate patient history and assessment findings to the patient's } \\
\text { presentation }\end{array}$ \\
\hline $\begin{array}{l}\text { LEVEL 4: } \\
\text { RELATING }\end{array}$ & $\begin{array}{l}\text { i. Conduct contextually sensitive interviews and safely assess } \\
\text { patients with a range of needs, in a variety of contexts and settings, } \\
\text { to produce clinically useful information. } \\
\text { ii. Interpret patient history and clinical diagnostic assessments to } \\
\text { establish initial clinical impressions. } \\
\text { iii. Refer patient for further diagnostic investigations, in light of the } \\
\text { patient's needs, the situation and the setting. }\end{array}$ \\
\hline
\end{tabular}

Raspovic, A. \& Pannan, L. (2013). Practical steps and collegiality in the building of podiatry curricula to meet accreditation and health sector employability demands 
each CLO ability would primarily be addressed. At times the location was relatively obvious,for example, structure of the foot would naturally be first addressed in anatomy subjects, however the location for delivery of other ability components was less clear.

This also saw the initial stage of gap and cross over identification. All ability statements were colour coded according to the year level in which they were primarily addressed, providing an immediate visual of the sequencing of subject delivery (Figure 2). As expected, the lower level CLO abilities tended to map to the start of the courses and the more complex outcomes resided in subjects at the end of the courses. Disparate sequencing of CLO abilities or delivery of outcomes too soon or too late in the courses could be easily considered through this powerful visual representation. Gaps and overlaps in the curriculum, plus inconsistencies in sequencing, could be identified and corrected. Key events at a program level were identified, such as readiness for external clinical placement, allowing identification of the abilities that were required to be achieved prior to students going off-campus to undertake practice-based learning as a member of a fully functioning clinical environment (i.e. hospitals, community health services, private podiatry practice).

The next stage was to orientate each CLO to subject/s and consider how the larger scope course outcome would be interpreted in the finer grain subject context. This interpretation was then used to write or adapt subject ILOs by contextualising and sometimes directly incorporating relevant CLO ability statements. This ensured the course outcome was adequately embedded within the subject. Subject ILOs are relatively detailed statements, affording subject coordinators a high level of flexibility and autonomy when marrying the course requirements with the vision of discrete subject goals. An example of how subject ILOs were structured and worded is offered in Figure 3.

Embedding the CLOs into subject ILOs throughout the courses was systematically undertaken for each CLO learning path, from cognitive level 1 to 4 , with adjustments made to amend black holes in the curriculum and unnecessary cross over. In reality this stage took several weeks and re-drafts, with much debate over content, scope, logistics, resourcing, integration, and bridging the theory-practice nexus. Important discourse opened up between staff on curriculum issues that tended not to be considered previously, as can happen when this level of introspective practice occurs. This stimulation of collaboration and collegiality is identified in the literature as a characteristic of the process (Uchiyama \& Radin, 2009).

\section{Figure 3: A Sample Subject Intended Learning Outcome (at AQF level 9)}

\section{Subject Intended Learning Outcome 2 (for Subject 1)}

On successful completion of this subject, you should be able to:

Nominate and justify assessments required for diagnosis of a patient and, given the results, diagnose the patient and classify their risk of developing serious foot-related complications from diabetes mellitus, and neurological and vascular disorders of relevance.

You should be able to:

1. Identify a comprehensive testing plan for a given patient presentation,

2. Diagnose serious complications, including ulceration, infection, Charcot's neuroarthropathy, chronic limb ischaemia and chronic venous insufficiency, from a selection of relevant indicators,

3. Classify risk for serious foot complications based on assessment and other related clinically important findings,

4. Justify the need for further assessment, such as diagnostic imaging, pathology and other diagnostic testing, based on a patient's presentation and individual circumstances. 
When the Podiatry CLOs had been fully embedded across the courses, and appropriately contextualised in subjects, teaching and learning activities and assessment tasks were systematically aligned with discrete subject ILOs. This process provides clear demonstration of the discrete learning opportunities through the course for students to build up and attain CLOs that, by design, are inclusive of the profession's (ANZPAC) competency standards. Furthermore, it shows consecutive, repeated and systematic assessment of each student's progress in developing and achieving the CLOs, providing convincing evidence that the final CLOs are successfully attained. This final step in the process goes explicitly to avoiding the fundamental issue identified by Bath and colleagues (2007) whereby the espoused, the enacted and the learnt curriculum are different enough that the original intent has not been met.

\section{The curriculum documents}

Documentation of the entire process is an important component of the approach used as it provides a tangible representation of the 'living curriculum'. A formal record of the 'point in time curriculum' can be used for several purposes and serves as the platform that will be revised and revisited as a record of curriculum evolution. Curriculum documents, systematically linking course outcomes to year levels, subjects, discrete subject ILOs, teaching and learning activities, and assessment tasks were produced. The Course Curriculum Map is the overarching curriculum document, showing pathways between CLOs and subject ILOs. An example section provided in Figure 4 demonstrates how this is structured, and shows how each subject contributes to the learning and assessment of level 3 abilities in the CLO 6 learning path seen in Figure 2.

Figure 4: Section of the Podiatry Course Curriculum Map: Integrating level of CLO 6 (Patient Interview \& Assessment)

\begin{tabular}{|c|c|c|c|}
\hline \multirow[b]{2}{*}{$\begin{array}{l}\text { Abilities underpinning each Course } \\
\text { Learning Outcome }\end{array}$} & \multicolumn{3}{|c|}{$\begin{array}{l}\text { Subject ILOs that address the } \\
\text { Course Learning Outcome }\end{array}$} \\
\hline & Subject $1^{*}$ & Subject 2 & $\begin{array}{l}\text { All subjects } \\
\quad \text { listed } \rightarrow\end{array}$ \\
\hline \multicolumn{4}{|l|}{ 6. PATIENT INTERVIEW \& ASSESSMENT } \\
\hline \multicolumn{4}{|l|}{ LEVEL 3: INTEGRATING } \\
\hline $\begin{array}{l}\text { 6.3.i. Select and justify the choice of } \\
\text { questions used in the patient interview }\end{array}$ & $2 a$ & $1 a$ & $x$ \\
\hline $\begin{array}{l}\text { 6.3.ii. Select and justify choice of assessment } \\
\text { techniques for a given patient }\end{array}$ & $2 a$ & $2 a, b$ & $x$ \\
\hline 6.3.iii. Present and explain assessment results & $2 b$ & $2 b, c, d$ & $x$ \\
\hline $\begin{array}{l}\text { 6.3.iv. Discuss why the defined normal and } \\
\text { abnormal ranges of structure and function } \\
\text { may or may not correlate with a patient's } \\
\text { presenting complaint }\end{array}$ & $2 b$ & $3 a, 3 d$ & $x$ \\
\hline $\begin{array}{l}\text { 6.3.v. Relate patient history and assessment } \\
\text { findings to the patient's presentation }\end{array}$ & $2 b, 2 c$ & $3 a, b ; 4 a, c$ & $x$ \\
\hline
\end{tabular}

*Note: Figure 3 above gives detail of ILO 2 for Subject 1.

Raspovic, A. \& Pannan, L. (2013). Practical steps and collegiality in the building of podiatry curricula to meet accreditation and health sector employability demands 
Examples of how the curriculum map is used routinely include reporting in student Subject Learning Guides. Relevant parts of the first two columns in Figure 4 may be used to communicate how their subject's ILOs align to CLO learning paths, for example, and linking this with assessment tasks indicates where they are evaluated. Alternatively, it can be provided in its entirety to regulatory and accreditation bodies as evidence towards achieving intended course goals.

\section{Considerations for evaluation, successes achieved and lessons learnt}

The final consideration in this case study is around evaluation of the approach described and the success of what was done. The key outcomes in this case are concerned with the effectiveness of the courses in ensuring comprehensive, aligned learning and producing graduates who are well prepared for the demands of industry. By default, it is taken that if these outcomes are achieved, the process must be appropriate. If the outcomes are not met, then the aspects of the curriculum approach and process responsible require identification and modification in order to refine the process. Evaluation of key outcomes can be undertaken as a multifaceted activity, through critical analyses arising from both routine, ongoing curriculum maintenance, for example; annual subject and course reviews, and quality activities designed to specifically ascertain the overall integrity of a course and its ability to achieve required course outcomes. The latter might include feedback from placement supervisors on student ability/competence, data from employers on work readiness and abilities of new graduates, and feedback from graduates after a period of employment around whether the courses were complete, well-sequenced and aligned with industry expectations. Evaluation of the process itself might include a critical review involving gathering feedback from staff and other key people who participated in the curriculum review process.

A significant indicator that the aims of curriculum re-design were fulfilled in this case is that the courses have been granted accreditation up to 2018 by the respective professional accreditation authority, the Australian and New Zealand Podiatry Accreditation Council (ANZPAC). Further support is given regarding the suitability of the curriculum as the national professional registration authority, the Podiatry Board of Australia, has accepted ANZPAC's accreditation recommendations and also approved the courses. That is, graduates of the courses are deemed suitably qualified to legally register for practice as a podiatrist in Australia. Informally, feedback from students, teaching staff and external clinical supervisors has been positive in terms of the students' knowledge and skill level as it relates to their expected level of clinical practice.

Several lessons have been learnt through undertaking this process that might be of use to others planning a similar project. Firstly, there were resource implications. Prolonged periods of staff time were required to design and develop the curricula, including several day long sessions and independent preparation in between. Experienced discipline staff were pivotal to the success of the process, although it is these people who were often the busiest and least able to afford ongoing effort due to competing commitments. And for this reason, staff buy-in was essential. The podiatry staff were aware of the purpose and importance of what was being done and therefore gave dedicated contributions. In addition, this process aligned with organisational directives at the time which created good incentive to participate. It was also found to be important to have dedicated support and assistance from an objective person with educational awareness, to drive the project in a guided and timely manner. Ideally, this person would be available to continue involvement until first graduates were finished. The final lesson learnt is that it is essential that the completion of the initial project is followed with a well laid out plan for curriculum maintenance and ongoing review. Given the dynamic nature of factors involved in the evolution of a curriculum, a routine method for review is required to avoid associated documentation becoming out dated and irrelevant.

Raspovic, A. \& Pannan, L. (2013). Practical steps and collegiality in the building of podiatry curricula to meet accreditation and health sector employability demands

Journal of Teaching and Learning for Graduate Employability, 4(1), 58-72. 


\section{Conclusion}

This paper provides a practical description of a process adopted to identify, embed and evidence CLOs throughout two vocationally orientated health sciences courses. It offers insights on anticipated and unexpected outcomes experienced during the design and development of the curricula. From an overall perspective this process was about enhancing educational quality in a rapidly changing world, through increasing transparency and accountability. And while there is a level of risk that prescriptive curriculum processes might encourage deductive and reductionist thinking, the experience was the opposite where the potential of what could be achieved created new and exciting possibilities. In addition, the process created opportunities for collegial discussion and debate on podiatry curriculum issues that are unlikely to have occurred to the same extent otherwise. Both the Faculty of Health Sciences curriculum design processes and the institutional Design for Learning initiative support the practice of 'explicit and systematic learning design' and in doing so promote clear communication, articulated minimum expectations and fairness through sound design. The effects of this aligned curriculum design process have had far reaching effect on the curricula, including a practical role in the classroom environment. And while it remains a work in progress and will require caretaking to ensure its currency and ongoing utility, this has proven a highly valuable exercise for the courses, students and staff. Maintenance and development of the curriculum map and associated resources/processes will form a key element of the Department of Podiatry's curriculum strategic plan. Further positive impact of this undertaking is also evident as the courses have been granted accreditation up to 2018 by the respective professional accreditation authority, the Australian and New Zealand Podiatry Accreditation Council (ANZPAC) and this recommendation has been accepted by the Australian regulatory authority for podiatrists, the Podiatry Board of Australia.

\section{Acknowledgments}

We wish to acknowledge staff from the Faculty of Health Sciences at La Trobe University, who generously donated their time, wisdom and enthusiasm to see this project to a successful completion: Associate Professor Fitzmaurice, Dr Adam Bird, Joanna Barrett, Daniel Bonanno, Matthew Cotchett, Nicoletta Frescos, Dr Karl Landorf, Dr Shannon Munteanu, Dr George Murley, Nikolaos Nikolopoulos, Craig Payne and Byron Perrin.

Raspovic, A. \& Pannan, L. (2013). Practical steps and collegiality in the building of podiatry curricula to meet accreditation and health sector employability demands 


\section{References}

Assessing \& Assuring Graduate Learning Outcomes (AAGLO) Project. (2011). AAGLO Summary 3: Challenges of assessing Graduate Learning Outcomes (GLOs) in workbased contexts. Retrieved February 8, 2013, from http://www.itl.usyd.edu.au/projects/aaglo/pdf/AAGLO Summary\%203 Final.pdf

Australian and New Zealand Podiatry Accreditation Council (ANZPAC). (2009a - updated 2012). Australian and New Zealand Podiatry Accreditation Council - Podiatry Competency Standards for Australia and New Zealand. Retrieved October 2, 2013, from http://www.anzpac.org.au/accreditation.html

Australian and New Zealand Podiatry Accreditation Council (ANZPAC). (2009b). Accreditation Standards and Procedures for Podiatry Programs for Australia and New Zealand. Retrieved October 2, 2013, from http://www.anzpac.org.au/accreditation.html

Australian Podiatry Association Victoria. (2012). About podiatrists. Retrieved February 8, 2013, from http://www.podiatryvic.com.au/Podiatrists/Podiatry.htm

Australian Learning and Teaching Council (ALTC). (2011). Learning \& Teaching Academic Standards (LTAS) Project Final Report for Architecture, Building, Education \& Science. Retrieved February 8, 2013, from http://www.olt.gov.au/resources?text=Learning+and+teaching+academic+standards

Australian Qualifications Advisory Board. (2007). Australian Qualifications Framework Implementation Handbook. (4 ${ }^{\text {th }}$ Ed). Retrieved February 8, 2013, from http://www.aqf.edu.au/Portals/0/Documents/Handbook/AQF Handbook 07.pdf

Bath, D., Smith, C., Stein, S. \& Swann, R. (2004). Beyond mapping and embedding graduate attributes: Bringing together quality assurance and action learning to create a validated and living curriculum. Higher Education Research \& Development, 23(3), $313-328$.

Biggs, J. \& Tang, C. (2007). Teaching for Quality Learning at University. (3rd ed.). Berkshire, England: McGraw Hill.

Bowden, J., Hart, G., King, B., Trigwell, K. \& Watts, O. (2000). Generic Capabilities of ATN University Graduates. Final Report to DETYA, Teaching and Learning Committee, Australian Technology Network.

Brooks, P. (2011). Health workforce issues for podiatry. Journal of Foot and Ankle Research, 4(Suppl 1), 12.

Faculty of Health Sciences 2009. Health Sciences Graduate Attributes Matrix: Developing the attributes. Faculty of Health Sciences Intranet, La Trobe University, viewed $8^{\text {th }}$ February 2013, https://intranet.latrobe.edu.au/health/teaching-and-learning/subjects

Forrester, K. \& Griffiths, D. (2011). Essentials of law for medical practitioners. Sydney: Churchill Livingstone.

Harden, R. (2001). AMEE Guide No 21: Curriculum mapping: A tool for transparent and authentic teaching and learning. Medical Teacher, 23(2), 123-137.

Hubball, H. \& Burt, H. (2004). An integrated approach to developing and implementing learning-centred curricula. International Journal for Academic Development, 9(1), 5165.

Jones, S., Dermoudy, J., Hannan, G., James, S., Osborn, J., Yates, B. \& Evans, C. (2007). Designing and mapping a generic attributes curriculum for science undergraduate students: A faculty-wide collaborative project. UniServe Science Teaching and Learning Research Proceedings, pp. 40-45.

Raspovic, A. \& Pannan, L. (2013). Practical steps and collegiality in the building of podiatry curricula to meet accreditation and 
Kelley, K., Coyle, J., McAuley, J., Wallace, L., Buerki, R. \& Frank, S. (2008a). Writing PharmD program-level, ability-based outcomes: Key elements for success. American Journal of Pharmaceutical Education, 72(5):98.

Kelley, K., McAuley, J., Wallace, L. \& Frank, S. (2008b). Curricular mapping: Process and product. American Journal of Pharmaceutical Education, 72(5):100.

La Trobe University. (2009). Design for Learning. Curriculum Review and Renewal at La Trobe University. Retrieved February 8, 2013, from http://www.latrobe.edu.au/about/downloads/DFL-booklet.pdf

La Trobe University. (2012). Vision 2015. Retrieved February 8, 2013, from http://www.latrobe.edu.au/about/vision

Oliver, B. (2011). Assuring graduate outcomes. Australian Learning \& Teaching Council Good practice report. Retrieved February 8, 2013, from

http://www.olt.gov.au/resource-assuring-graduate-outcomes-curtin-2011

Robley, W., Whittle, S. \& Murdoch-Eaton, D. (2005). Mapping generic skills curricula:

Outcomes and discussion. Journal of Further and Higher Education, 29(4), 321-330.

Schnock, W. (1989). Annotations to the History of Chiropody-Podiatry in Victoria 1929-1979. Malvern, Victoria, Australia: Walter Schnock.

Spencer, D., Riddle, M. \& Knewstubb, B. (2012). Curriculum mapping to embed graduate capabilities. Higher Education Research \& Development, 31(2) 217-231.

Sumsion, J. \& Goodfellow, J. (2004). Identifying generic skills through curriculum mapping: A critical evaluation. Higher Education Research \& Development, 23(3) 329-346.

Tertiary Education Quality Standards Agency (TEQSA). (2011). Developing a framework for teaching and learning standards in Australian Higher Education and the role of TEQSA: Discussion paper. Retrieved February 8, 2013, from

$<$ http://www.innovation.gov.au/HigherEducation/Policy/TertiaryEducationQualityAndStan dardsAgency/Documents/teqsa/Teaching Learning Discussion Paper.pdf>

Uchiyama, K. \& Radin, J. (2009). Curriculum mapping in higher education: A vehicle for collaboration. Innovative Higher Education, 33, 271-280.

Raspovic, A. \& Pannan, L. (2013). Practical steps and collegiality in the building of podiatry curricula to meet accreditation and health sector employability demands 